\title{
Geri Dönüştürülmüş Karbon Karasının Killi Zeminlerin Kıvam Limitlerine Etkisi
}

\author{
Fatih IȘIK¹, Rahim Kağan AKBULUT ${ }^{1}$
}

ÖZET: Günümüzde, atık malzemelerin geri dönüştürülmesi dünya çapında önem arz etmektedir. Geri dönüşümle çevresel problemlerin önüne geçilmesinin yanı sıra ekonomik katkılar da sağlanmaktadır. Geri dönüşșürülmüş karbon karası $(\mathrm{KKg})$, hurda lastiklerin pirolizi sonucunda elde edilen bir geri dönüşüm malzemedir. Bu çalışmada, KKg'nin killi zeminlerin kıvam limitlerine olan etkisi incelenmiştir. Bu amaçla iki farklı kil kullanılmıştır; yüksek plastisiteli kil $(\mathrm{CH})$ ve düşük plastisiteli kil (CL). Killerin içine kuru ağılılıça \%0, \%1, \%3, \%5 ve \%10 oranında KKg katılarak karışımlar hazırlanarak likit limit ve plastik limit deneyleri yapılmışıtır. Deney sonuçlarından $\mathrm{CH}$ kilin likit limit değerinin $\% 1 \mathrm{KKg}$ içeriğinde, $\% 0 \mathrm{KKg}$ içeriğine göre ani olarak düştüğü ve $\mathrm{KKg}$ arttıkça azalma eğilim hızının düşerek devam ettiği belirlenmiştir. Diğer taraftan, $\mathrm{CH}$ kilin plastik limit değerinin ise $\% 1 \mathrm{KKg}$ içeriğine kadar arttığı ve bu noktadan sonra KKg arttıkça azaldığı tespit edilmiştir. CL kilin likit limitinde ise gözle görülür bir düşüşün olmadığı ve benzer şekilde CL kilin plastik limit değerlerinde de önemli bir düşüşün olmadığı belirlenmiştir.

Anahtar Kelimeler: Geri dönüşüm, karbon karası, kıvam limitleri, killi zeminler

\section{Effect of Recycled Carbon Black on Consistency Limits of Clayey Soils}

\begin{abstract}
Nowadays, the recycling of waste materials is one of the important tasks in the world. Not only does it solve the environmental problems but also the economic return provides. The recycled carbon black $(\mathrm{CBr})$ is obtained by recycling of scrap tires using pyrolysis method. In this study, the effect of $\mathrm{CBr}$ on consistency limits of clayey soils was investigated. Two different types of clayey soils were used; the first one was high plastic clay $(\mathrm{CH})$ and the other one was low plastic clay $(\mathrm{CL})$. The $\mathrm{CBr}$ was mixed with both clays in $0 \%, 1 \%, 3 \%, 5 \%$ and $10 \%$ percentages at dry state. The liquid and plastic limit tests were performed on the mixtures and also on pure $(0 \%)$ clayey soils. It is observed that the liquid limit value of $\mathrm{CH}$ clay decreases sharply between $0 \%$ and $1 \% \mathrm{CBr}$ contents and then this decreasing trend goes on smoothly. On the other hand, the plastic limit value of $\mathrm{CH}$ clay increases with increasing $\mathrm{CBr}$ contents, achieves a maximum value at $1 \% \mathrm{CBr}$ content and then starts to decrease beyond this $\mathrm{CBr}$ content. There is no considerable decrease discovered on liquid limit values of CL clay. With a similar manner, the plastic limit value of CL clay decreases with an increase in $\mathrm{CBr}$ contents, however, this decreasing trend is not remarkable.
\end{abstract}

Keywords: Recycling, carbon black, consistency limits, clayey soils

\footnotetext{
Fatih IŞIK (0000-0003-3641-3512), Rahim Kağan AKBULUT (0000-0002-6342-1019), Atatürk Üniversitesi, Erzurum Meslek Yüksekokulu, İnşaat Bölümü, ERZURUM, Türkiye

Sorumlu yazar/Corresponding Author: Fatih IŞIK, fatih.isik@atauni.edu.tr

Bu çalışma 09-11 Ekim 2017 tarihinde Iğdır-Türkiye'de düzenlenen II. International Iğdır Symposium'unda sunulmuş ve kongre özet kitabında yayınlanmıştır.
} 


\section{GİRIŞ}

Çağımızda dünya çapında yaşanan önemli problemlerden biri de atık malzemelerin sebep olduğu çevresel problemlerdir. Endüstrileşmeye ve nüfus artışına paralel olarak ortaya çıkan atık malzemeler ihtiva ettikleri bileşenlerden dolayı doğada uzun yıllar kalabilmekte ve çevre kirliliğine neden olmaktadır. Günümüzde atık malzemelerin geri dönüştürülmesi dünya çapında önem kazanmıştır. Atık malzemelerin geri dönüştürülerek tekrar kullanımı öncelikli olarak ham madde ihtiyacını azaltarak doğal kaynakların sürdürülebilmesini sağlanmaktadır. Diğer taraftan geri dönüşümle, atık malzemelerin doğaya verdikleri zararlar engellenmektedir. Ayrıca geri dönüşümle, çevresel problemlerin önüne geçilmesinin ve doğal kaynakların sürdürülebilirliğinin yanı sıra ekonomik katkılar da ortaya çıkmaktadır.

İnşaat sektöründe atık malzemelerbetonüretiminde, karayolu yapımında ve zeminlerin iyileştirilmesinde farklı şekillerde değerlendirilmektedir. Kullanılamaz durumda olan betonarme yapıların yıkımından sonra ortaya çıkan atık beton kütlelerin öğütülüp agrega olarak kullanılabilirliği üzerine çalışmalar yapılmıştır (Duan and Poon, 2014; Pedro et al., 2014; Silva et al., 2016; Ismail et al., 2017; Letelier et al., 2017). Benzer şekilde atık asfalt kaplamaların tekrar kullanımı araştırmacılar tarafından incelenmiştir (Tabaković et al., 2010; Arulrajah et al., 2012; Hoy et al., 2016; Ojum and Thom, 2017). Cam atıklar öğütülüp geri dönüştürülerek beton katkısı olarak kullanılmıştır (Grubb et al., 2006; Disfani et al., 2012; Kampala et al., 2013).

Atık malzemeler zeminlerin iyileştirilmesinde de kullanılmıştır. Bu amaçla, boro-jips (Tulek, 2007; Coruh ve ark., 2013; Kutuk-Sert and Kutuk; 2012), fosfo-jips (Shen et al., 2007; Yilmaz and Civelekoglu, 2009; Shen et al., 2009), silis dumanı (Kalantari et al., 2011; Al-Azzawi et al., 2012; Negi et al., 2013; Gupta and Sharma, 2014) ve uçucu kül (Edil et al., 2006; Chauhan et al., 2008; Brooks, 2009) kullanılmıştır.

Hurda lastikler de atık bir malzeme olup ömrünü tamamlamış, yıpranmış veya kullanılamayacak durumda olan araba lastiklerinin atılması ile oluşur. Vahşi depolama alanlarında hurda lastikler gelişi güzel ve düzensiz bir şekilde biriktirilmektedirler (Şekil 1). Bu durum çevre problemlerine neden olmaktadır; birinci olarak, vahşi depolamadan dolayı hacimsel olarak büyük deponi alanlarına ihtiyaç duyulması, ikinci olarak ise düzensiz depolamanın haşereler vb. gibi zararlıların barınmasına zemin hazırlaması ve son olarak da lastiklerin ihtiva ettiği bileşenler ile bu bileşenlerin doğada uzun süre kalmasıdır.

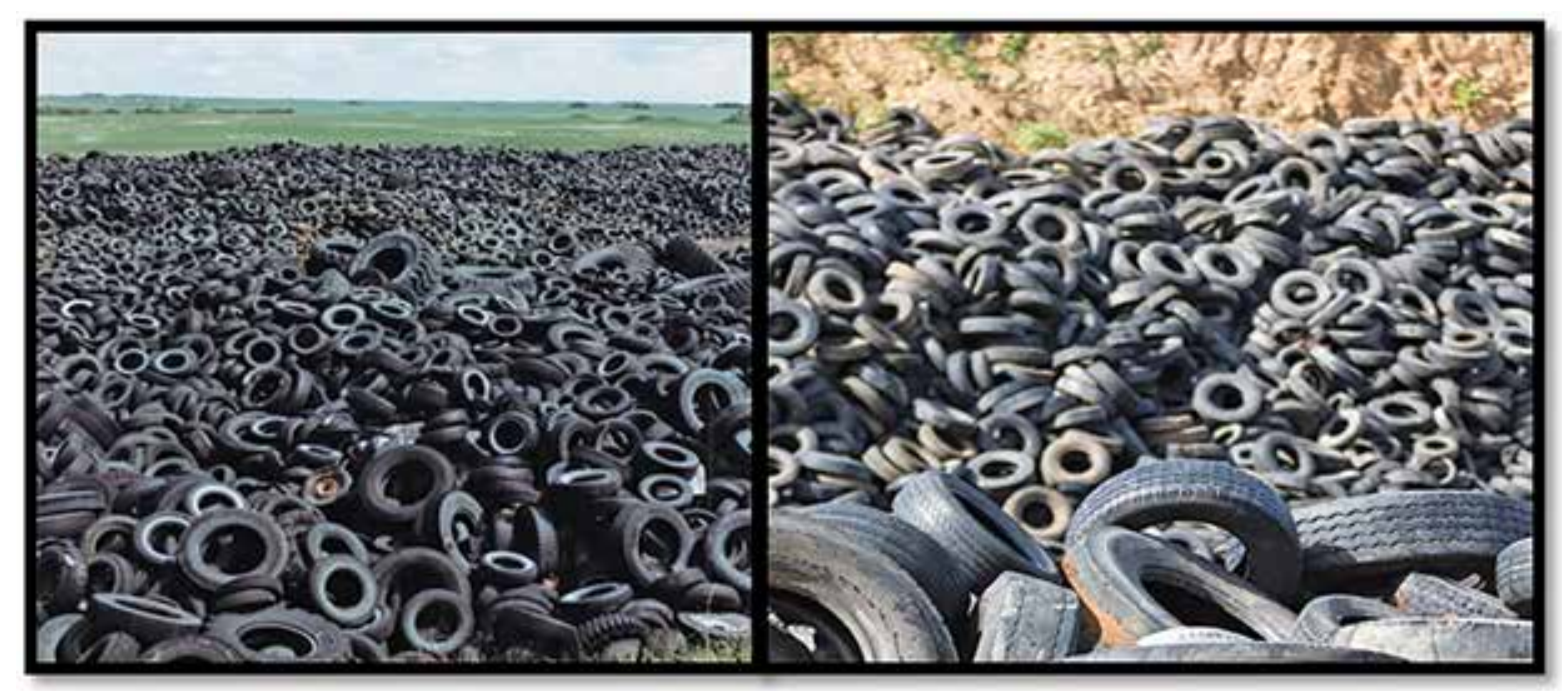

Şekil 1. Hurda lastikler ve vahşi depolama alanı (Anonim ${ }^{(1)}$; Anonim $^{(2)}$ )

Geri dönüştürülerek granül hale getirilen hurda lastiğin inşaat sektöründe kullanılabilirliği üzerine birçok araştırma yapılmıştır. Edil and Bosscher
(1994) granül lastiğin zeminlerdeki mühendislik özelliklerini incelemişlerdir. Masad et al. (1996) lastik ve zemin karışımının hafif dolgu malzemesi 
olarak kullanılabilirliğini araştırmışlardır. Edinçliler et al. (2010) kullanılmış lastiklerin toprak dolguların mekanik özelliklerine etkisini incelemişlerdir. Sheikh et al. (2013) kum ve granül lastik karışımlarının kayma ve sıkışabilirlik özelliklerini araştırmışlardır. Brunet et al. (2016) geri dönüştürülmüş granül lastiklerin sismik izolatör olarak kullanılabilirliğini incelemişlerdir. Son yıllarda çelik tellerinden ayrıştırılmış hurda lastikler piroliz metodu kullanılarak daha verimli bir geri dönüşüme tabi tutulmaktadırlar. Piroliz, oksijensiz ortamda organik maddelerin yüksek sıcaklıklara (500$1000^{\circ} \mathrm{C}$ ) maruz birakılarak termal olarak bozunmas 1 işlemidir. Oksijensiz ortamda belirli basınç ve sıcaklığa maruz bırakılan hurda lastiklerden, piroliz işleminin her bir safhasında oluşan bozunma süreçlerine bağlı olarak farklı ürünler orta çıkmaktadır. Bu ürünler; gaz, pirolitik yağ ve karbon karasıdır.

$\mathrm{Bu}$ çalışmada hurda lastiklerin geri dönüşümüyle elde edilen karbon karasının (KKg) killi zeminlerin kıvam limitlerine olan etkisi incelenmiştir. Bu amaçla, iki farklı kil zemine kuru ağılıkça farklı oranlarda KKg katılarak likit ve plastik limit deneyleri yapılmış ve sonuçlar irdelenmiştir.

\section{MATERYAL VE YÖNTEM}

\section{Kil Zeminler}

Deneylerde kullanılan killi zeminler Erzurum Oltu ilçesinden temin edilmiştir. Getirilen killi zeminler renklerine bakılarak Beyaz (B) ve Kahverengi (K) olarak adlandırılmıştır. Killi zeminler üzerinde yapılan indeks deneylerinden Beyaz kilin likit limit ve plastik limit değerleri sırasıly $\% 119.7$ ve \%30.4 olarak tespit edilmiştir. Beyaz kil Birleştirilmiş Zemin Sınıflandırma (USCS) sistemine göre yüksek plastisiteli $(\mathrm{CH})$ kil sınıfina girmektedir. Diğer taraftan, Kahverengi kil üzerinde yapılan indeks deneylerinde likit limit değeri \%35.7 ve plastik limit değeri ise \%23.6 olarak belirlenmiştir. Kahverengi kil USCS'ye göre düşük plastisiteli (CL) kil sınıfına girmektedir.

\section{Geri Dönüştürülmüş Karbon Karası}

Geri dönüştürülmüş karbon karası $(\mathrm{KKg})$ Erzincan'da hurda lastikleri geri dönüştüren Prokom adli şirketten temin edilmiştir. Şirket, hurda lastikleri ilk olarak parçalama ile çelik tel ve granül lastik parçaları üretmekte ve ikinci aşamada ise piroliz yöntemi ile pirolitik yağ ve karbon karası elde etmektedir. Ürettiği pirolitik yağı enerji amaçlı kullanırken karbon karasını farklı boyutlarda paketleyerek piyasaya sürmektedir. KKg üzerinde yapılan temas açısı analizinden KKg'nin su itici (hidrofob) bir malzeme olduğu tespit edilmiştir (Şekil 2). Temas açısı, malzeme üzerine bırakılan su damlasının malzeme ile yaptığı açının belirlenmesi ile tespit edilir. Şekil 2.a'da KKg'nin temas açısı 144 - $150^{\circ}$ aralığında çıkmıştır. Bu değeri anlamlandırmak amaciyla Şekil 2.b'de Beyaz kilin temas açısı analiz sonucu verilmiştir. Şekil 2.b'den Beyaz kilin temas açısının $22^{\circ}$ oluğu ve damlatılan suyu emdiği görülmektedir. Bu kapsamda Beyaz kilin suyu seven (hidrofilik) bir malzeme olduğu belirlenmiştir. Benzer şekilde Kahverengi kil üzerinde yapılan analizden ise temas açısı değeri $15-17^{\circ}$ aralığında tespit edilmiştir.

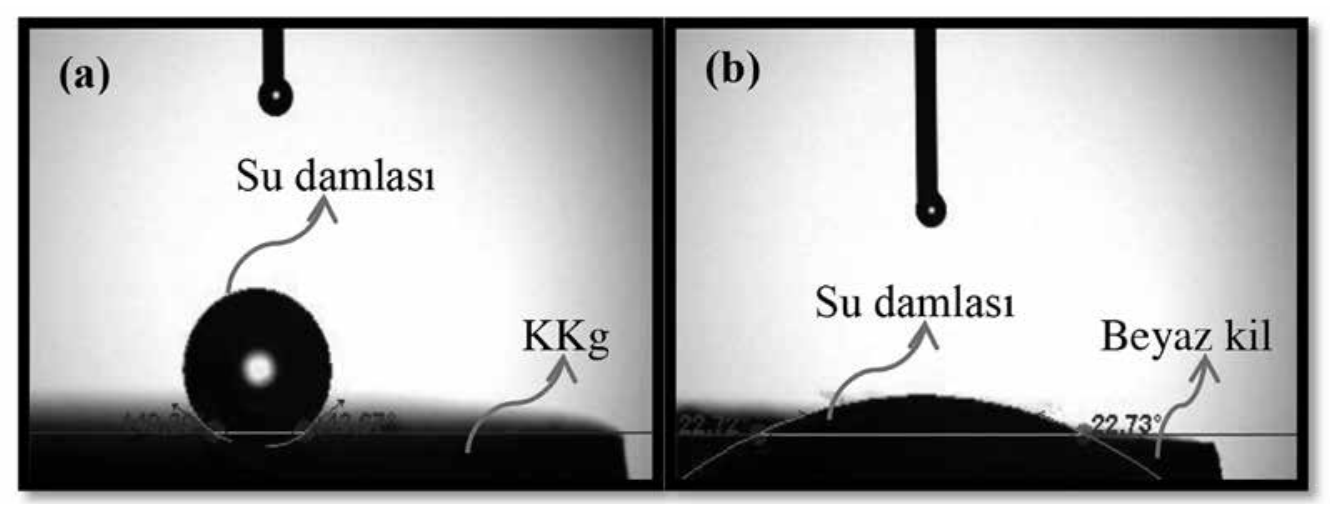

Şekil 2. (a) KKg'nin (b) Beyaz kilin temas açısı analiz sonucu

Diğer taraftan, KKg üzerinde yapılan SEM analizinde, $\mathrm{KKg}$ 'nin nano boyutta olduğu belirlenmiştir
(Şekil 3). Şekilden de görüleceği gibi KKg'nin boyutu 40 - 45 nano metre arasında değişmektedir. 


\section{KKg ve Kil Karışımları}

KKg'nin Beyaz ve Kahverengi kilin kıvam limitlerine etkisini incelemek amaciyla kil zeminlere kuru ağırlıkça \%1, \%3, \%5 ve \%10 oranlarında $\mathrm{KKg}$ katılarak kuru halde karıştırılmıştır. Karışım isimleri ve KKg yüzdeleri Çizelge 1'de verilmiştir.

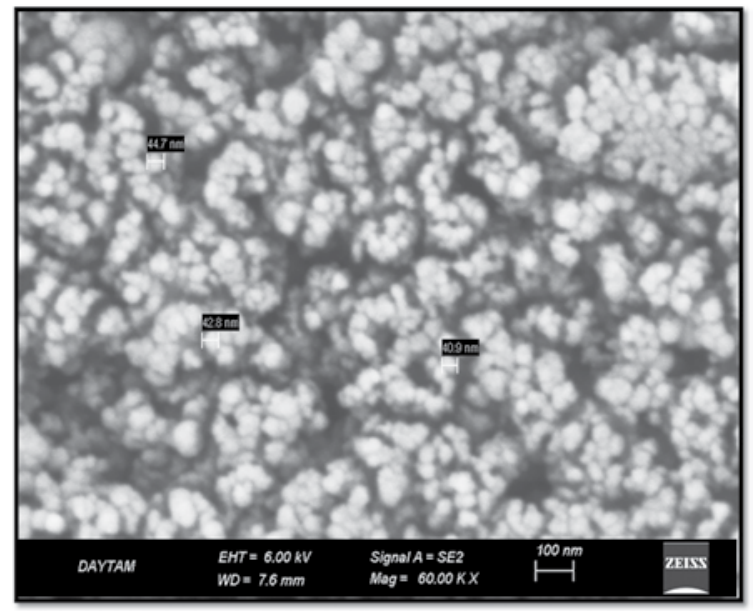

Şekil 3. KKg’nin SEM analiz sonucu

Çizelge 1. Karışım yüzdeleri

\begin{tabular}{|c|c|}
\hline $\begin{array}{c}\text { Karıșım } \\
\text { İsmi }\end{array}$ & $\begin{array}{c}\text { KKg } \\
\text { Yüzdesi }\end{array}$ \\
\hline B0 & $\% 0$ \\
\hline B1 & $\% 1$ \\
\hline B3 & $\% 3$ \\
\hline B5 & $\% 5$ \\
\hline B10 & $\% 10$ \\
\hline
\end{tabular}

\section{Kıvam Limitleri}

Karışımların likit limit (LL) değeri İngiliz standardına (BS 1377-2) göre düşen koni yöntemi kullanılarak belirlenmiş olup plastik limit (PL) değerlerinin belirlenmesi için ise Amerikan standard1 (ASTM D 4318-98) kullanılmıştır. Belirlenen miktarlarda $\mathrm{KKg}$ tartılarak kil zemin numunelerine katılmıştır. KKg'nin homojen bir

\begin{tabular}{|c|c|}
\hline $\begin{array}{c}\text { Karısıım } \\
\text { İsmi }\end{array}$ & $\begin{array}{c}\text { KKg } \\
\text { Yüzdesi }\end{array}$ \\
\hline $\mathrm{K} 0$ & $\% 0$ \\
\hline $\mathrm{K} 1$ & $\% 1$ \\
\hline $\mathrm{K} 3$ & $\% 3$ \\
\hline $\mathrm{K} 5$ & $\% 5$ \\
\hline $\mathrm{K} 10$ & $\% 10$ \\
\hline
\end{tabular}

şekilde karışım içine dağılması için $15 \mathrm{dk}$ süre ile kuru olarak karıştırılmıştır. Daha sonra karışımlara ilgili standartlar gereği su ilave edilmiş ve tekrar karıştırılmıştır (Şekil 4). Elde edilen karışım numunelerin suyu adsorbe edebilmeleri için plastik kaplarda ağzı kapalı olarak 24 saat süre ile bekletilmiştir. Süre sonunda likit limit ve plastik limit deneyleri her bir karışım için ayrı ayrı yapılmıştır.

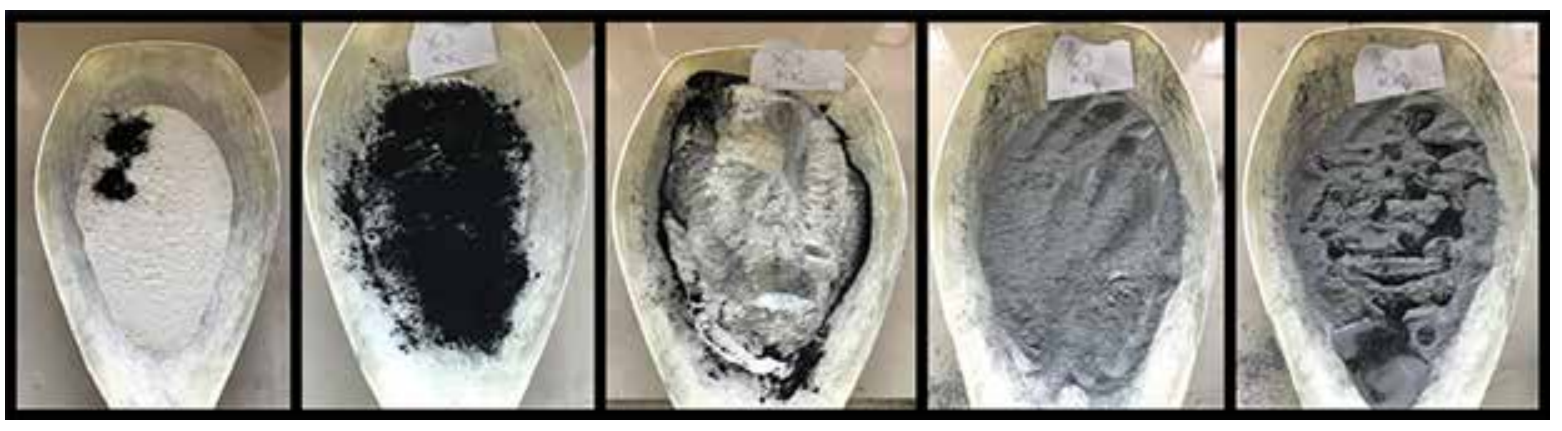

Şekil 4. Karışımların hazırlanması 


\section{ARAŞTIRMA BULGULARI}

Karışımlar üzerinde yapılan likit ve plastik limit deney sonuçları Çizelge 2'de verilmiştir. Çizelge 2 incelendiğinde, Beyaz killi karışımların likit limit (LL) değerlerinin $\mathrm{KKg}$ arttıkça azaldığ 1 buna

Çizelge 2. Kıvam limitleri deney sonuçları

\begin{tabular}{|c|c|c|c|}
\hline Karışım & $\begin{array}{c}\text { LL } \\
(\%)\end{array}$ & $\begin{array}{c}\text { PL } \\
\mathbf{( \% )}\end{array}$ & $\begin{array}{l}\text { IP* } \\
\mathbf{( \% )}\end{array}$ \\
\hline B0 & 119.7 & 30.4 & 89.3 \\
\hline B1 & 90.4 & 38.9 & 51.5 \\
\hline B3 & 88.4 & 36.8 & 51.6 \\
\hline B5 & 89.8 & 37.1 & 52.7 \\
\hline B10 & 82.8 & 35.6 & 47.2 \\
\hline
\end{tabular}

(*) IP (Plastisite İndisi) = LL - PL

Şekil 5'te KKg'nin karışımların likit limitine olan etkisi grafiksel olarak verilmiştir. Şekil incelendiğinde Beyaz killi karışımların LL değerinin $\% 0-\% 1 \mathrm{KKg}$ içerikleri arasında ani olarak \%119.7 değerinden \%90.4 değerine azaldığ 1 ve bu noktadan sonra azalma eğilim hızının düşerek devam ettiği ve $\% 10 \mathrm{KKg}$ 'de \%82.8 değerine düştügü görülecektir. Diğer taraftan karşılık plastik limit (PL) değerlerinin ise arttığ 1 görülmektedir. Diğer taraftan plastisite indisi (IP) değerinin de likit limite benzer bir davranış gösterdiği belirlenmiştir. Kahverengi killi karışımlarda ise $\mathrm{KKg}$ arttıkça LL ve PL değerlerinin azaldığı, IP değerlerinin ise azalıp-arttığ 1 tespit edilmiştir (Çizelge 2).

\begin{tabular}{|c|c|c|c|}
\hline Karışım & $\begin{array}{c}\text { LL } \\
\mathbf{( \% )}\end{array}$ & $\begin{array}{c}\text { PL } \\
\mathbf{( \% )}\end{array}$ & $\begin{array}{c}\text { IP* } \\
\mathbf{( \% )}\end{array}$ \\
\hline K0 & 35.7 & 23.6 & 12.1 \\
\hline K1 & 32.6 & 21.5 & 11.1 \\
\hline K3 & 34.3 & 21.3 & 13.0 \\
\hline K5 & 31.7 & 21.3 & 10.4 \\
\hline K10 & 33.3 & 21.1 & 12.2 \\
\hline
\end{tabular}

Kahverengi killi karışımların LL değerlerinde de bir azalma eğiliminin olduğu ancak Beyaz killi karışımlarda olduğu gibi kayda değer bir azalmanın olmadığ 1 tespit edilmiştir (Şekil 5). Kahverengi kilin LL değeri $\% 0 \mathrm{KKg}$ 'de \%35.7 iken $\mathrm{KKg}$ artışıyla kademeli olarak azalmış ve \%10 KKg'de \%33.3 değerine düşmüştür.

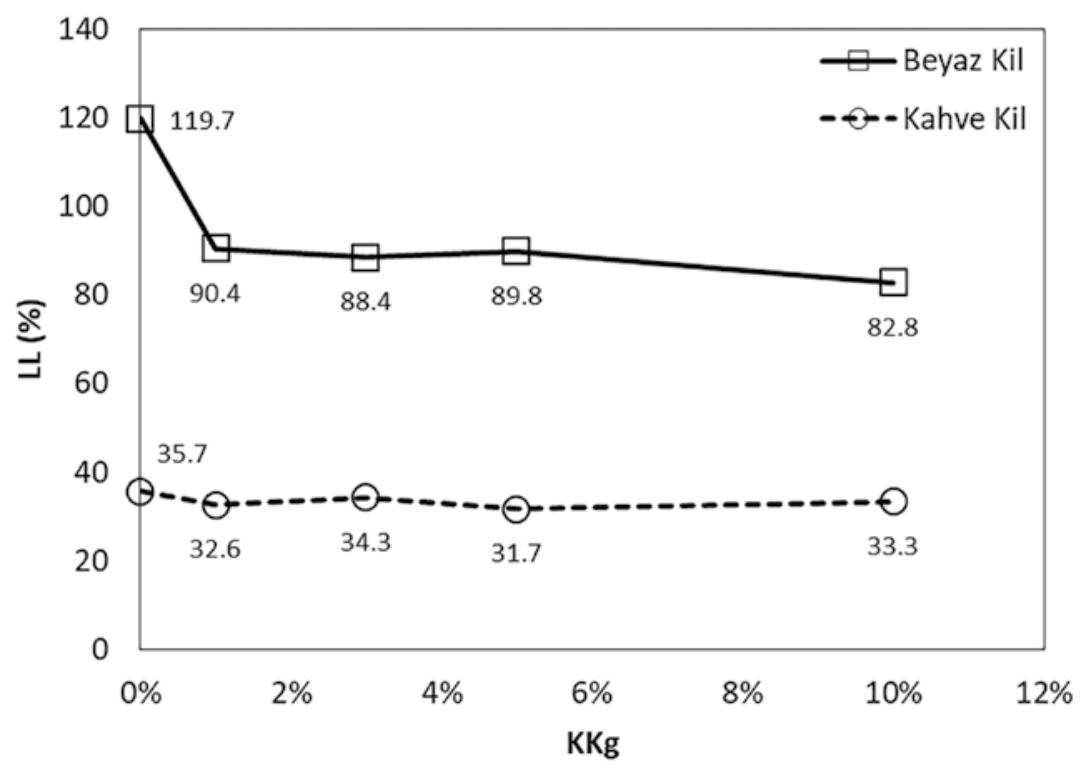

Şekil 5. LL - KKg ilişkisi

Şekil 6'da ise PL - KKg ilişkisi verilmiştir. Beyaz killi karışımların PL değerinin $\% 0$ - \%1 KKg aralığında ani olarak \%30.4 değerinden \%38.9 değerine arttı̆̆ ve $\% 1 \mathrm{KKg}$ içeriğinden sonra kademeli olarak azalarak \%10 KKg'de \%35.6 değerine düştüğü belirlenmiştir (Şekil 6).
Kahverengi killi karışımlarda ise PL değerinin \%0 - \%1 $\mathrm{KKg}$ arasında \%23.6’ten \%21.5 değerine düştüğü ve bu noktadan sonra azalma eğiliminin ihmal edilecek kadar az olduğu tespit edilmiştir (Şekil 6). 


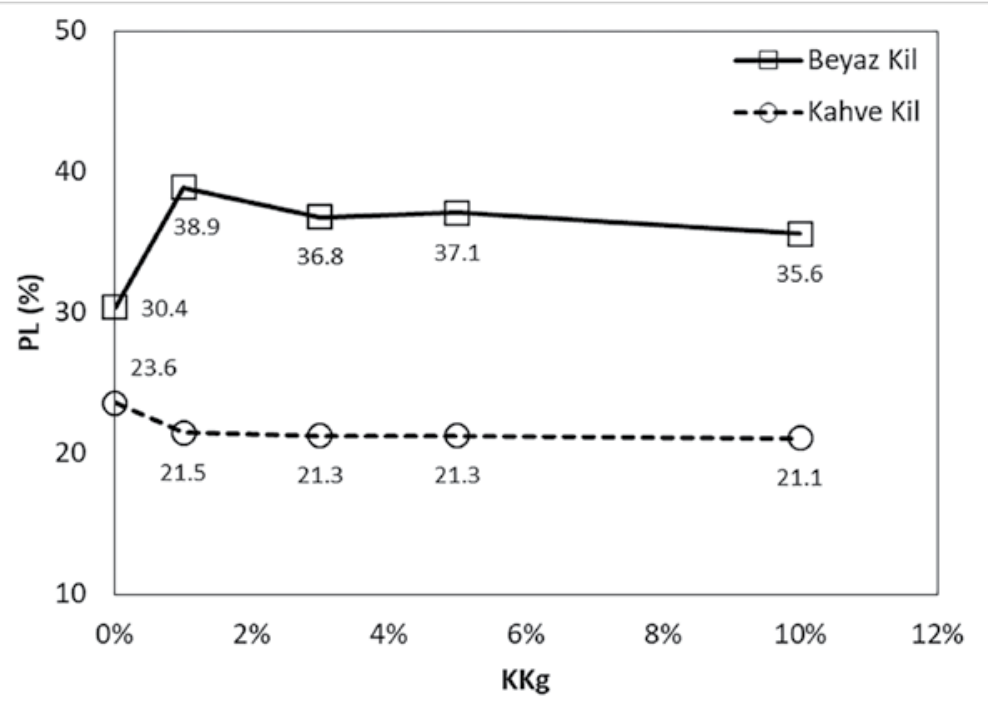

Şekil 6. PL - KKg ilişkisi

KillizeminlerinUSCS'yegöresınıflandırılmasında kullanılan Cassagrande kartına karışımların likit limit - plastisite indisi değerleri işaretlenmiştir (Şekil 7). Kart üzerindeki yığılmalardan dolayı Kahverengi killi karışımlar Detay-1 olarak Şekil 7.b'de verilirken Beyaz killi karışımlar Detay-2 olarak Şekil 7.c'de gösterilmiştir. Kahverengi killi karışımları (K0, K1, K3, K5 ve K10) Cassagrende kartında CL sinıfinda ve A-hattına yakın konumlanmışlardır (Şekil 7.b). $\mathrm{Bu}$ durum KKg'nin düşük plastisiteli (CL) killerin davranışına etkisinin ihmal edilebilecek kadar az olduğunu göstermektedir. Diğer taraftan, Beyaz kil (B0) Cassagrande kartında A-U hattı arasında ve U-hattına yakın konumlanırken, KKg katkılı B1, B3, B5 ve B10 karışımları aşağıda ve A-hattına yakın olarak konumlanmışlardır. B1, B3, B5 ve B10 karışımları USCS'ye göre CH olarak sınıflandırılsalar da katk1 sonrası üzerinde deney yapılan $\mathrm{CH}$ kilin $\mathrm{KKg}$ etkisiyle yüksek plastisiteli silt (MH) sınıfına geçebileceği görülmektedir (Şekil 7.c).

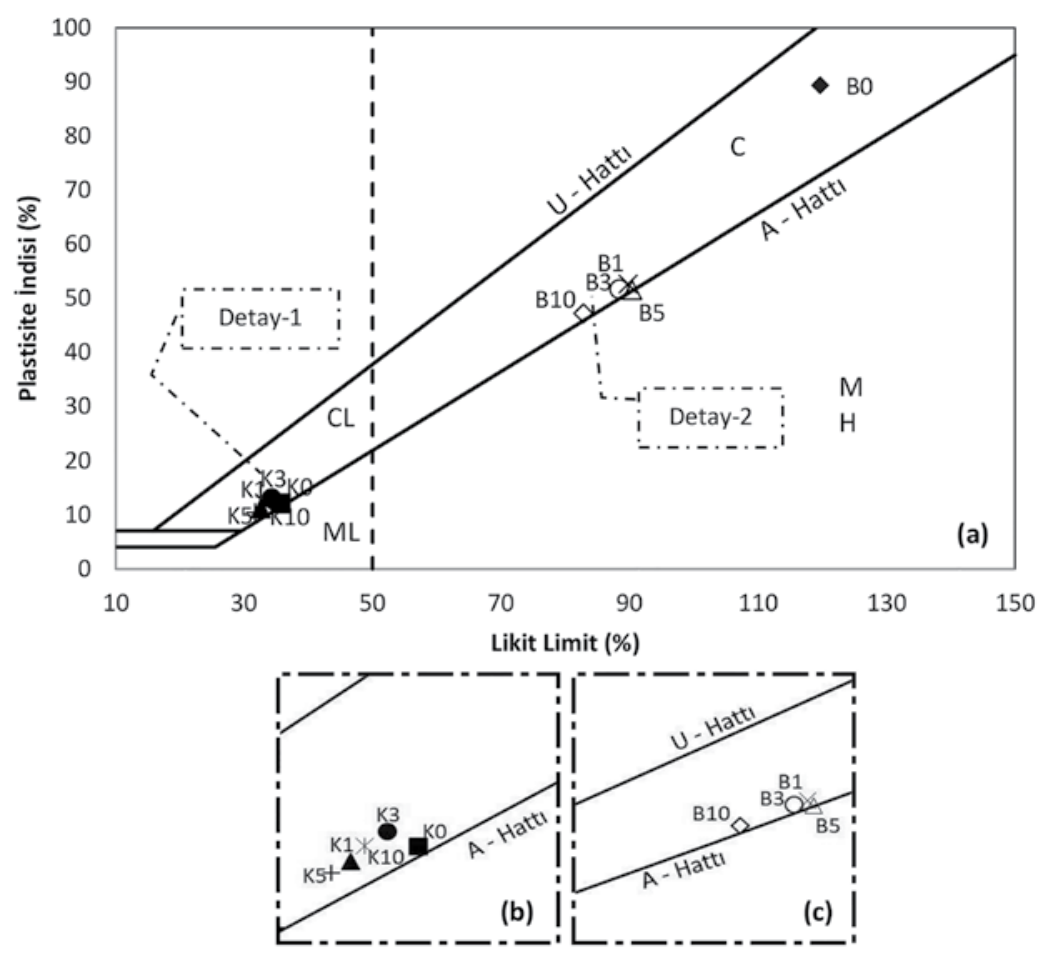

Şekil 7. (a) Cassagrande kartı, (b) Detay-1, (c) Detay-2 


\section{SONUÇ}

Bu çalışmada hurda lastiklerin geri dönüştürülmesi ile elde edilen KKg'nin killi zeminlerin kıvam limitlerine olan etkisi incelenmiştir. Kullanılan KKg'nin nano boyutlu ve hidrofob bir malzeme olduğu belirlenmiştir. Çalışmada kapsamında iki farklı kil kullanılmıştır. Beyaz kil, yüksek plastisiteli bir kil olup USCS'ye göre $\mathrm{CH}$ sinıfina girmektedir. Kahverengi kil, düşük plastisiteli olup USCS'ye göre CL sınıfına girmektedir. Genel olarak, KKg'nin Beyaz kile olan etkisi ile Kahverengi kile olan etkisi farklı olmuştur. Yapılan çalışma ışında aşağıdaki sonuçlara ulaşılmıştır.

\section{Beyaz Kile Olan Etkisi}

Üzerinde deney yapılan beyaz kilin likit limit (LL) değerlerinin KKg arttıkça azaldığı buna karşılık plastik limit (PL) değerlerinin ise arttığı görülmektedir. Diğer taraftan plastisite indisi (IP) değerinin de likit limite benzer bir davranış gösterdiği belirlenmiştir. Üzerinde deney yapılan beyaz kilin LL değerinin $\% 0$ - \%1 KKg içerikleri arasında ani olarak \%119.7 değerinden \%90.4 değerine azaldığ 1 ve bu noktadan sonra azalma eğilim hızının azalarak devam ettiği ve $\% 10 \mathrm{KKg}$ 'de \%82.8 değerine düştüğü belirlenmiştir. Üzerinde deney yapılan beyaz kilin PL değeri $\% 0-\% 1 \mathrm{KKg}$

\section{KAYNAKLAR}

Al-Azzawi DAA, Daud KA, Sattar MAA, 2012. Effect of Silica Fume Addition on the Behavior of Silty-Clayey Soils. Journal of Engineering and Development, 16(1).

Anonim $^{(1)}$; http://www.kocaelitv.com.tr/haber/bir-ayda-30-ton-atiklastik-toplandi-h12507.html (Erişim tarihi: 10 Aralık, 2017).

Anonim $^{(2)}$; http://www.tirex.com.tr/english/why-exhibit.htm (Erişim tarihi: 10 Aralık, 2017).

Arulrajah A, Piratheepan J, Disfani MM, Bo MW, 2012. Geotechnical and geoenvironmental properties of recycled construction and demolition materials in pavement subbase applications. Journal of Materials in Civil Engineering, 25(8): 1077-1088.

ASTM D 4318-98 2000. Standard test method for liquid limit, plastic limit, and plasticity index of soils. ASTM International, West Conshohocken, PA, USA.

Brooks RM, 2009. Soil stabilization with fly ash and rice husk ash. International Journal of Research and Reviews in Applied Sciences, 1(3): 209-217.

Brunet S, de la Llera JC, Kausel E, 2016. Non-linear modeling of seismic isolation systems made of recycled tire-rubber. Soil Dynamics and Earthquake Engineering, 85: 134-145. aralığında ani olarak \%30.4 değerinden \%38.9 değerine arttığ azalarak \%10 KKg'de \%35.6 değerine düştüğü tespit edilmiştir. Üzerinde deney yapılan yüksek plastisiteli $(\mathrm{CH})$ kilin $\mathrm{KKg}$ ile muamele edilmesi sonucunda zemin davranışının değişeceği belirlenmiştir. $\mathrm{Bu}$ durumun $\mathrm{KKg}$ 'nin hidrofob bir malzeme olması ve su ile kil arasındaki yük dengesinin değişmesinden kaynaklandığı düşünülmektedir.

\section{Kahverengi Kile Olan Etkisi}

Üzerinde deney yapılan kahverengi kilde $\mathrm{KKg}$ arttıkça LL ve PL değerlerinin azaldığı, IP değerlerinin ise azalıp-arttığı tespit edilmiştir. Üzerinde deney yapılan kahverengi kilin LL değerlerinde de bir azalma eğiliminin olduğu ancak Beyaz kilde olduğu gibi kayda değer bir azalmanın olmadığı tespit edilmiştir. Üzerinde deney yapılan kahverengi kilin LL değeri $\% 0 \mathrm{KKg}$ 'de \%35.7 iken KKg artışıyla kademeli olarak azalmış ve $\% 10 \mathrm{KKg}$ 'de $\% 33.3$ değerine düşmüştür. Diğer taraftan, PL değerinin \%0 - \%1 KKg arasında $\% 23.6$ 'ten $\% 21.5$ değerine düştüğü ve bu noktadan sonra azalma eğiliminin ihmal edilecek kadar az olduğu tespit edilmiştir. Üzerinde deney yapılan CL kile KKg'nin etkisi ihmal edilebilecek düzeyde olduğu belirlenmiştir.

Chauhan MS, Mittal S, Mohanty B, 2008. Performance evaluation of silty sand subgrade reinforced with fly ash and fibre. Geotextiles and Geomembranes, 26(5): 429-435.

Coruh E, Hinisoglu S, Kocakerim M, Arasan S, Oltulu M, 2013. Investigation of the usage of borogypsum in the subbase course as a stabilization material, "EÜFBED - The Graduate School of Natural and Applied Sciences Journal", 6(2): 221231. [in Turkish]

Disfani MM, Arulrajah A, Bo MW, Sivakugan N, 2012. Environmental risks of using recycled crushed glass in road applications. Journal of Cleaner Production, 20(1): 170-179.

Duan ZH, Poon CS, 2014. Properties of recycled aggregate concrete made with recycled aggregates with different amounts of old adhered mortars. Materials \& Design, 58: 19-29.

Edil TB, Bosscher PJ, 1994. Engineering properties of tire chips and soil mixtures. Geotechnical testing journal, 17(4): 453-464.

Edil TB, Acosta HA, Benson CH, 2006. Stabilizing soft fine-grained soils with fly ash. Journal of Materials in Civil Engineering, 18(2): 283-294.

Edinçliler A, Baykal G, Saygılı A, 2010. Influence of different processing techniques on the mechanical properties of used tires in embankment construction. Waste Management, 30(6): 1073-1080. 
Grubb DG, Gallagher PM, Wartman J, Liu Y \& Carnivale III M, 2006. Laboratory evaluation of crushed glass-dredged material blends. Journal of Geotechnical and Geoenvironmental Engineering, 132(5): 562-576.

Gupta C \& Sharma RK, 2014. Influence of micro silica fume on sub grade characteristics of expansive soil. International Journal of Civil Engineering Research, 5(1): 77-82.

Hoy M, Horpibulsuk S, Rachan R, Chinkulkijniwat A \& Arulrajah A, 2016. Recycled asphalt pavement-fly ash geopolymers as a sustainable pavement base material: Strength and toxic leaching investigations. Science of The Total Environment, 573: $19-26$.

İsmail S, Kwan WH \& Ramli M, 2017. Mechanical strength and durability properties of concrete containing treated recycled concrete aggregates under different curing conditions. Construction and Building Materials, 155: 296-306.

Kalantari B, Prasad A, Huat BB, 2011. Stabilising peat soil with cement and silica fume. Proceedings of the Institution of Civil Engineers-Geotechnical Engineering, 164(1): 33-39.

Kampala A, Horpibulsuk S, Chinkullijniwat A \& Shen SL, 2013. Engineering properties of recycled calcium carbide residue stabilized clay as fill and pavement materials. Construction and Building Materials, 46: 203-210.

Kütük-Sert T, Kütük S, 2012. Physical and Marshall properties of borogypsum used as filler aggregate in asphalt concrete. Journal of Materials in Civil Engineering, 25(2): 266-273.

Letelier V, Tarela E, Muñoz P \& Moriconi G, 2017. Combined effects of recycled hydrated cement and recycled aggregates on the mechanical properties of concrete. Construction and Building Materials, 132: 365-375.

Masad E, Taha R, Ho C, \& Papagiannakis T, 1996. Engineering properties of tire/soil mixtures as a lightweight fill material. Geotech. Test. J., 19(3): 297-304

Negi C, Yadav RK, Singhai AK, 2013. Effect of silica fume on index properties of black cotton soil. Int J Sci Eng Res, 4(8): 828-833.
Ojum C, Thom N, 2017. Effect of binder in recycled asphalt on cold-mix pavements. Proceedings of the Institution of Civil Engineers-Construction Materials, 1-6.

Pedro D, De Brito J, Evangelista L, 2014. Influence of the use of recycled concrete aggregates from different sources on structural concrete. Construction and Building Materials, 71: $141-151$

Sheikh MN, Mashiri MS, Vinod JS \& Tsang H, 2013. Shear and Compressibility Behavior of Sand-Tire Crumb Mixtures. Journal of Materials in Civil Engineering,25(10): 1366-1374

Shen W, Zhou M, Zhao Q, 2007. Study on lime-fly ashphosphogypsum binder. Construction and Building Materials, 21(7): 1480-1485.

Shen W, Zhou M, Ma W, Hu J, Cai Z, 2009. Investigation on the application of steel slag-fly ash-phosphogypsum solidified material as road base material. Journal of Hazardous Materials, 164(1): 99-104.

Silva RV, de Brito J, Dhir RK, 2016. Establishing a relationship between modulus of elasticity and compressive strength of recycled aggregate concrete. Journal of Cleaner Production, 112: $2171-2186$

Standard B, 1990. Methods of test for soils for civil engineering purposes. BS1377.

Tabaković A, Gibney A, McNally C \& Gilchrist MD, 2010. Influence of recycled asphalt pavement on fatigue performance of asphalt concrete base courses. Journal of Materials in Civil Engineering, 22(6): 643-650.

Tulek M, 2007. A study of the use of chemical waste gypsums in soil stabilization. Balıkesir Üniversitesi Fen Bilimleri Enstitüsü, Yüksek lisans Tezi.

Yilmaz I, Civelekoglu B, 2009. Gypsum: an additive for stabilization of swelling clay soils. Applied Clay Science, 44(1): 166-172. 